The Geneva Papers on Risk and Insurance, 22 (No. 82, January 1997), 46-59

\title{
Financing Old-age Dependency in Europe: Towards Overall Management of Old-age
}

\author{
by Jacques Blondeau* and David Dubois**
}

\section{Introduction}

Any serious response to the challenge of dependency in the elderly inevitably involves our defining a welfare package for old-age that goes well beyond the current provision of pensions and medical care. And yet, cover of dependency risk in the elderly has long been an issue that our social welfare systems have overlooked. Although Government commitment has been by no means negligible, for dependency provision, we must still lean heavily on family solidarity. Whether for want of resources, for lack of interest or because minds have been engaged elsewhere, the issue of dependency in the elderly has remained outside the focus of political activity precisely at a time when population trends have begun to lend it renewed relevance and urgency.

Demography has for several years been entering a «greying» phase, a trend which is now typical of most Western countries. This «greying» or ageing of the population is not without problems: financing retirement, adapting the health system to suit an older population, ... and, more generally, rethinking society's overall approach to managing age. These developments are beginning to call into question the notion that has hitherto prevailed, of a kind of «social contract» between the generations. Indeed, what is now required is a reorganisation and a thorough reappraisal of the place of the elderly in our societies.

\section{Population ageing and dependency in the elderly}

During the 20th century there has been a spectacular increase in life expectancy brought about by a fall in the infant mortality rate combined with a rise in the number of

\footnotetext{
* Chairman and Chief Executive Officer of SCOR. Leader.

** Visiting Lecturer and researcher, University of Paris II Pantheon Assas - SCOR VIE, Project
} 
the elderly (thanks to advances in medicine, improved hygiene and work conditions and to personal strategies for «wear and tear reduction»,...). In France in 1960, life expectancy at birth was 73 years for women and 67 years for men. In 1995, a new-born baby boy could expect to live until the age of 73.8 years and a baby girl to 81.9 years, a relative increase in average life expectancy, that is, of $10 \%$. This situation in not particular to France; all European countries have experienced a similar trend.

Life expectancy at birth - Men

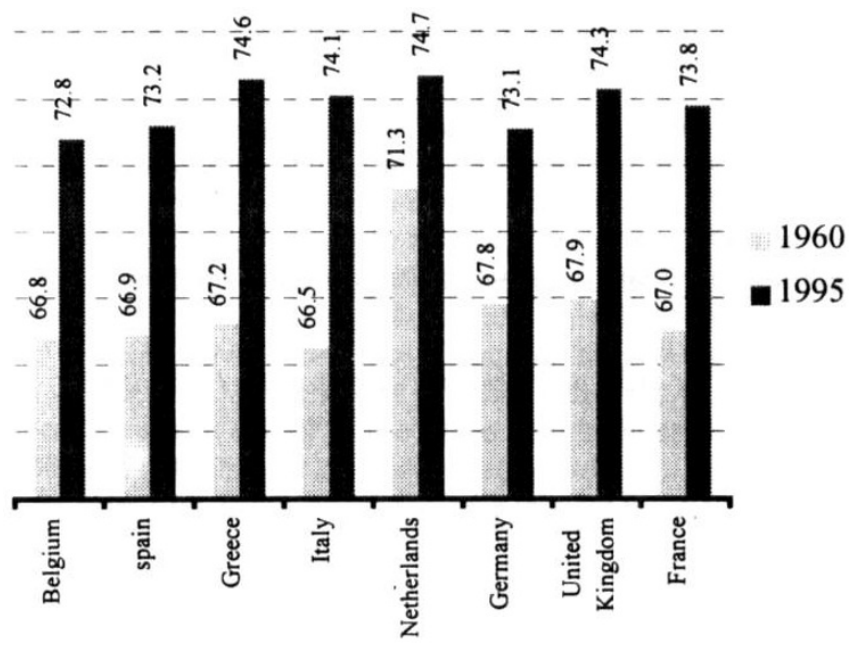

Life expectancy at birth - Women

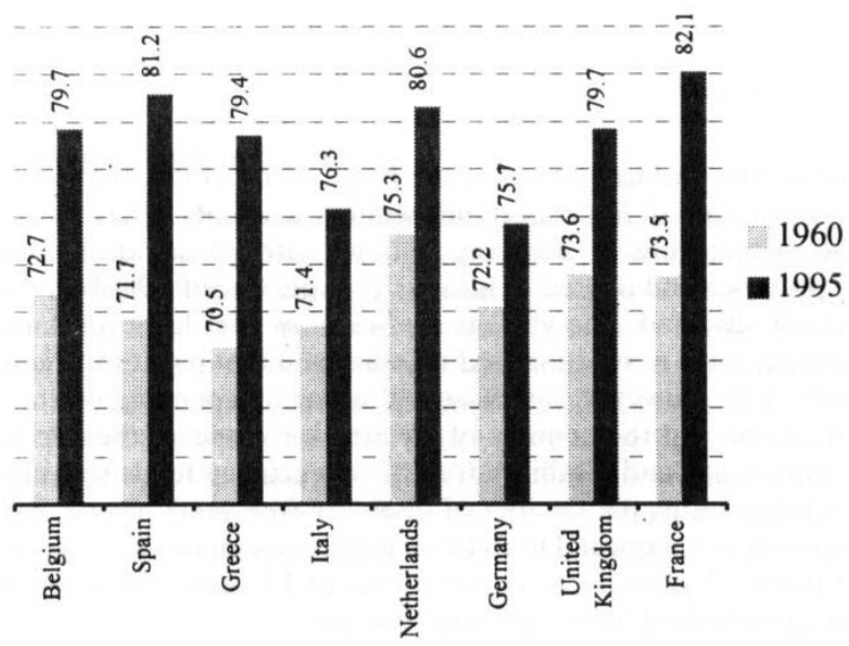


The reason for this increase in life expectancy is the dramatic fall in mortality throughout Europe, primarily of infant mortality, but also due to great improvements in the survival prospects of the elderly. Until around 1960, improved life expectancy was the result of a fall in the mortality rate for under fifteen year-olds and a reduction in the infant mortality rate. But over the last thirty years, increase in life expectancy has been due to a sharp fall in the mortality rate for adults and to improvement in the survival prospects of the elderly. These «new» causes of improved average life expectancy make predictions about maximum possible life expectancy especially difficult since we still do not know a great deal about the mechanics of the ageing process. For their part, the demographers tell us that life expectancy should continue to climb to between 85 and 90 years, with eventually a single expectancy for both sexes.

While, from the human point of view, it is undeniable that improved life expectancy has meant real progress for our populations, for a true appreciation of the implications of this phenomenon we must be mindful of two important factors. On the one hand, we need to be sure that the additional years are years of good health and, on the other, we need to be able to monitor and anticipate the potential economic and social impacts of this average lengthening of human life.

Life expectancy at birth - projections 1995 - 2020

Men

\begin{tabular}{|c|c|c|c|}
\cline { 2 - 4 } \multicolumn{1}{c|}{} & Belgium & Spain & Greece \\
\hline 1995 & 72.8 & 73.2 & 74.6 \\
\hline 2010 & 75.6 & 73.4 & 77.7 \\
\hline 2020 & 77.3 & 73.5 & 77.7 \\
\hline & Netherlands & France & U. Kingdom \\
\hline 1995 & 74.7 & 73.7 & 74.3 \\
\hline 2010 & 76.0 & 76.4 & 76.7 \\
\hline 2020 & 76.0 & 78.0 & 77.6 \\
\hline
\end{tabular}

Women

\begin{tabular}{|c|c|c|c|}
\cline { 2 - 4 } \multicolumn{1}{c|}{} & Belgium & Spain & Greece \\
\hline 1995 & 79.7 & 81.2 & 79.4 \\
\hline 2010 & 82.6 & 81.3 & 82.0 \\
\hline 2020 & 84.2 & 81.3 & 82.0 \\
\hline & Netherlands & France & U. Kingdom \\
\hline 1995 & 80.6 & 82.0 & 79.7 \\
\hline 2010 & 81.4 & 84.8 & 81.8 \\
\hline 2020 & 81.5 & 86.5 & 82.6 \\
\hline
\end{tabular}

Source: EUROSTAT 1995

In modelling the physical effects of the lengthening of life, the experts have come up with a new concept, that of life expectancy without disability. They have devised a way of measuring the average life by breaking it down into phases or age situations broadly reflecting the presence and degree of incapacity experienced - disability free, slightly disabled, and severely disabled. The various studies show that life expectancy and disabilityfree life expectancy have moved forward together and that part of the gain in length of life is in good health with, however, significant differences depending on the age at which the criteria are observed and the country of observation. Indeed, the gap in absolute terms between life expectancy and disability-free life expectancy tends to widen with advanced age while in relative terms the number of disability-free years has increased considerably. France is in this respect atypical. Disability-free life expectancy at 65 years has risen sharply since 1970 from 7.3 years to its present level of 12 years; while for other countries it appears to have levelled off between 8 and 10 years. 


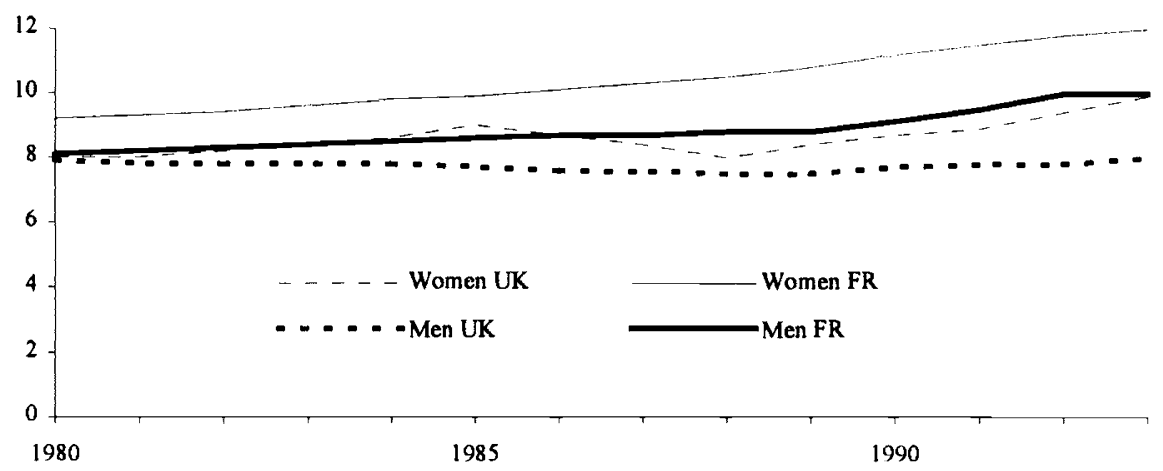

The incidence of disability in the very old is still high, the percentage of handicapped persons increasing with age. While the prevalence of severe disability in the elderly has fallen, that of chronic disabling disease has risen, giving rise to growing demand for assistance with the activities of daily life. Dependency provision has thus become unavoidable and will require a special structure suited to the kinds of service to be provided and also to their means of funding. To do this, we carefully need to delineate what exactly we mean by dependency, for its provision has a price and any misunderstanding on the part of the population at large as to what it involves could engender excesses, the dimension of which it is still difficult to predict.

\begin{tabular}{|c|c|}
\hline Age & $\begin{array}{c}\text { Percentage of handicapped persons } \\
\text { (all degrees) }\end{array}$ \\
\hline 70 & $7 \%$ \\
\hline 80 & $10 \%$ \\
\hline 90 & $40 \%$ \\
\hline 95 & $65 \%$ \\
\hline
\end{tabular}

\section{The notion of dependency in the elderly}

Dependency is a subjective notion whose definition and scope are based on criteria which vary from one individual to the next. The problem of producing a clear and simple definition makes especially difficult the task of establishing a provision structure which, at one and the same time, meets the needs of the individual and avoids moral hazard and anti-selection. In general, a person is described as dependent if he or she requires the help of another person in order to perform the activities of daily living (ADL). This definition is based on the studies of the American Katz which have helped to develop the concept of ADL. The concept covers all the basic acts of everyday existence which, in theory, are easy to measure objectively. For Katz, a person ceases to be autonomous when he or she ceases to be able to perform these everyday acts alone: taking a bath - getting dressed and undressed - washing, combing their hair, shaving - standing up, lying down, sitting down, moving about - going to the toilet - eating and drinking; those acts which we master first as 
babies being in principle those which we lose control of last as we age. Although there exists no universally accepted standard for ADL, many insurance companies use the concept for certifying dependency.

Dependency can be described as a chronic risk in the sense that a person remains autonomous up to a certain age and thereafter requires the help of another person for the performance of many daily activities. Most elderly people eventually need the help of another person, but this need can vary enormously from one individual to the next. And it is precisely this variation in need which is so tricky to define and which increases the chances of moral hazard. Insurance companies have tended to obviate this difficulty by refusing to cover partial disability in preference to total disability. Insurers use a variety of definitions of total disability. As a rule, loss of autonomy is measured as a score reflecting the degree or level of assistance required, in terms of the time the outside assistant needs to spend with the dependent individual. As examples, let us take the definitions used by operators on the French market. Members of the National Federation of French Mutuals, as part of an insurance product called «The Mutex Independence Plan», define two dependency levels determined by the score achieved by the dependent individual - partial dependency ( 26 to 32 points) and total dependency (over 32 points) according to the following assessment system:

\begin{tabular}{lccc}
\hline & $\begin{array}{c}\text { Unassisted without or with } \\
\text { difficulty }\end{array}$ & $\begin{array}{c}\text { With some } \\
\text { assistance }\end{array}$ & $\begin{array}{c}\text { With full assistance - totally } \\
\text { dependent }\end{array}$ \\
\hline Eating & 0 & 3 & 10 \\
\hline Getting dressed & 0 & 3 & 10 \\
\hline Personal hygiene & 0 & 3 & 10 \\
\hline Moving & 0 & 3 & 10 \\
\hline Going to the toilet & 0 & 3 & 10 \\
\hline
\end{tabular}

Another entity, the Bureau Commun des Assurances Collectives, uses a second method which is based on the time spent by the carer in assisting the dependent individual. This definition is based on an evaluation of the longest interval of autonomy during the day and of the care-time required in any 24 hour period. The term «longest interval of autonomy» means the lapse of time during which an individual can cope alone without supervision. The sum of the care-time in any 24 hours period is expressed as an aggregate derived from the answers to a medical questionnaire. The degree of dependency is set at one of four levels - from 0 (totally independent) to 3 (totally dependent) according to the following table:

\begin{tabular}{cccc}
\hline Degree of dependency & $\begin{array}{c}\text { Interval of autonomy } \\
\text { during the day }\end{array}$ & \multicolumn{2}{c}{$\begin{array}{c}\text { Aggregate care-time } \\
\text { over } 24 \text { hours }\end{array}$} \\
\hline 0 & $>4$ hours & or & 2 hours \\
\hline 1 & 2 to 4 hours & or & 2 to 4 hours \\
\hline 2 & $1 / 2$ to 2 hours & or & 4 to 6 hours \\
\hline 3 & $<1 / 2$ hour & or & $>6$ hours \\
\hline
\end{tabular}

In addition, the individual is certified permanently disabled if he or she is incapable of performing the ADL without the assistance of a carer, or requires supervision in order to avoid danger to himself or herself or to someone else. 
Finally, a third criterion used by French insurers is based on dependency as defined by Social Legislation. Under the latter, a person is dependent if he or she:

- is totally and permanently physically incapable of performing alone at least three of the following 4 reference activities: moving about, getting dressed, washing, and eating, and thereby justifies the assistance of a carer or transfer to a dedicated institution;

- is suffering from senile dementia or Alzheimer's disease;

- is awarded Class 3 invalidity status by the French Social Security, i.e. «is permanently recognised as being unable to perform any remunerative occupation or work and as a consequence must have recourse to outside assistance to perform the everyday activities of life» (Art. L 314-4 of the French Social Security Code).

These examples of definitions used on the French market are evidence of the existence of a wide variety of approaches to interpreting the concept of dependency. Under the circumstances, where legislation exists, sticking to the letter of the law would appear to be the best solution!

If defining dependency is no easy task, deciding what it means in practice is, by comparison, fairly simple: hygiene and health needs, assistance with everyday living, and sometimes the need for transfer to an institution. There remains the problem of supplying assistance which is suited to the habits and preferences of the dependent individual. The cost of such assistance is, moreover, something that cannot be borne by the elderly persons or by the family single-handed. The question then arises: who is to bear its cost? In order to provide adequate cover for such risk, welfare insurance schemes will have to be set up involving the payment of contributions or premia over part of the life cycle in the knowledge that benefits will be enjoyed only towards its terminal phase. But who, exactly, in the public and private sectors, is best placed to minimise the risk of such schemes being «worked» and of their cost getting out of hand?

\section{The public assistance solution: social insurance and dependency}

The accelerated «greying» of the European population makes it both necessary and urgent to set up a dedicated system for the management of dependency in the elderly. With ageing comes the need to develop new markets for the elderly, a sector which has thus far not been sufficiently explored and which should possess great potential for job creation. According to Council of Europe estimates, the dependent account on average for from 12 to $18 \%$ of the population of over 65 year-old.

\section{Population ageing and dependency}

\begin{tabular}{|l|c|c|c|}
\hline & $\begin{array}{c}\text { Total dependants } \\
\text { over 65 years (all levels) }\end{array}$ & $\begin{array}{c}\text { Total population over } \\
\text { 65 years }\end{array}$ & $\begin{array}{c}\text { Ratio of dependants to } \\
\text { able-bodied over 65 years }\end{array}$ \\
\hline France & 1400000 & 8665000 & $16,1 \%$ \\
\hline Germany & 1650000 & 12507000 & $13,2 \%$ \\
\hline United Kingdom & 1380000 & 9239000 & $14,9 \%$ \\
\hline
\end{tabular}

Source: Council of Europe 
Most European countries run aid schemes for the elderly which are, as a rule, tied in with other services provided either under pension- or handicap-allowance schemes, or through social assistance systems, or again as exceptions to services which were not originally designed to benefit the dependent elderly. And it is precisely because their nature and the decentralised systems for their management (regional and local) vary so enormously that it is difficult to generalise about the services provided under such schemes. Ultimately, all social systems in European countries supply assistance of this kind, but since the latter is not always built into the social welfare system, it is by no means always properly adapted to the specific needs of the dependent and, as a consequence, does not always measure up to expectations regarding quality of service and cost.

Hence the concern of three governments - Germany, France and the United Kingdom - to rationalise such assistance and to establish systems which clearly focus on providing a customised service to the dependent elderly. In all three cases the advantages of the new system are twofold:

- on the one hand, the dependent elderly enjoy full recognition as a separate social category;

- and, on the other, private insurers are furnished with a homogeneous definition of dependency upon which they can model their offer and thereby play a fuller part as purveyors of complementary insurance.

\subsection{Dependency provision - the German model}

After twenty years of debate, the law on Dependency in the Elderly was unanimously adopted on 28 May 1994. It establishes dependency as a recognised state and dependency insurance as a fifth branch of social insurance alongside sickness, old-age, unemployment and occupational accident. Implementation of this new insurance will be in three phases. Payment of contributions commences on 1 January 1995. On 1 April 1995, dependencyrisk cover will take effect and a first round of benefits will be paid to persons living at home. As of 1 July 1996, persons placed in special institutions will be entitled to benefits. Contributions have been set at $1 \%$ of the gross wage which is subject to the same ceiling as old-age insurance. Payment of the contribution differs according to the status of the contributor.

\begin{tabular}{ccc}
\hline Status of insured & Employee contribution & Outside-entity contribution \\
\hline Wage-earner & $1 / 2$ by employee & $1 / 2$ by employer \\
\hline Retiree & $1 / 2$ by retiree & $1 / 2$ by pension fund \\
\hline Public servant & $1 / 2$ by public servant & $1 / 2$ by special social scheme \\
\hline
\end{tabular}

Membership is compulsory for all German citizens, but the Government leaves them the option of contributing either to public insurance or to a private body, in the knowledge, having brought its provision into line with the private sector, that benefits under either system are strictly equivalent. $90 \%$ of the insureds have opted for public insurance. The increase in the employer contribution has been offset by abolishing, with the agreement of almost all the Länder, one non-work day. In two Länder, which refused the offer, the additional charge is borne entirely by the insured. On 1 July 1996 , the $1 \%$ rate was raised to $1.7 \%$ to cover extension of benefits to persons in special institutions. 
Previously, old-age dependency costs were covered by sickness insurance without any specific increase in contributions. Since 1 January 1995, however, the cost of dependencyrisk cover is no longer borne by the sickness insurance branch, although its management is still the responsibility of the sickness insurance funds. Some 700,000 persons, previously benefiting from a dependency allowance, have now all been taken on by the new insurance.

The law defines three degrees of dependency, based on the individual's inability to perform certain essential everyday activities and on the duration of outside assistance required in any 24 -hour period.

\begin{tabular}{cll}
\hline Level & Degree of dependency & Duration of assistance per day \\
\hline I & High & $\begin{array}{l}11 / 2 \text { hour at least per day - unable to perform } 2 \text { essential activities } \\
\text { alone. }\end{array}$ \\
\hline II & Very high & 3 hours at least per day - unable to perform 3 essential activities alone \\
\hline III & Severe & Round-the-clock assistance \\
\hline
\end{tabular}

The law divides essential activities into four separate categories: personal hygiene (washing, combing the hair, shaving, going to the toilet), feeding (eating and drinking), movement (getting up, lying down, getting dressed and undressed, walking, mounting the stairs, going out), house-work (shopping, cleaning, doing the washing).

Benefits are independent of the dependent person's income, being based on the degree of dependency as determined by the person's GP or sickness-insurance doctor. The level of benefit will also depend on whether the person is at home or in a special institution.

\begin{tabular}{ccc}
\hline $\begin{array}{c}\text { Degree of } \\
\text { dependency }\end{array}$ & $\begin{array}{c}\text { Benefit for care dispensed } \\
\text { by family at home }\end{array}$ & $\begin{array}{c}\text { Benefit for care dispensed } \\
\text { by professional carers at home }\end{array}$ \\
\hline Level I & $400 \mathrm{DM}$ & $750 \mathrm{DM}$ \\
\hline Level II & $800 \mathrm{DM}$ & $1800 \mathrm{DM}$ \\
\hline Level III & $1300 \mathrm{DM}$ & $2800 \mathrm{DM}$ \\
\hline
\end{tabular}

To these benefits under the system established by law should be added certain other forms of special assistance, for example, with the purchase of equipment or, when the carer is on leave (up to a maximum of four weeks), a special allowance of $2800 \mathrm{DM}$ to pay for a replacement. These benefits, while falling well short of real dependency-generated costs, make even so a substantial contribution to providing a first layer of basic dependency care. The monthly cost of care in a special institution is somewhere between 2000 and $8000 \mathrm{DM}$, depending on the degree of disability, leaving from 2000 to $4000 \mathrm{DM}$ to come from the pocket of the dependent individual or the family. There is clearly an opportunity for complementary welfare here. From an economic standpoint, projections so far indicate that the system will continue in balance provided the number of dependants does not climb too sharply over the next few years, something that cannot be ruled out. For the time-being, the system remains healthily solvent thanks to the three-month time lag which has made possible savings of close on 17 billion DM - between the levying of contributions and commencement of benefit payments. 


\subsection{The autonomy benefit - the French model}

Following an initiative by the authorities, the autonomy-benefit scheme was officially presented by the Government on 18 September 1995 . It was originally designed to come into force on 1 January 1996 for dependants living at home and on 1 January 1997 for dependants in special institutions. At the time of its presentation, however, the scheme was found to contain a number of grey areas which the authorities were not immediately able to clarify and which, after re-examination, led to its entry into force being postponed until 1 January 1997. It was intended to finance this new insurance by redeploying Departmental funds recovered from the scrapping of the Third Party Indemnity Benefit currently paid to the dependent elderly. Redeployment of such sums would have generated 9 billion Francs, some 11 billion Francs short of the 20 billion estimated cost of the new allowance. The proposed solution to this shortfall was a direct levy on the Old-age Solidarity Fund which is in part financed from the CSG or General Social Charge. This would have meant either raising the rate of the latter or extending its contribution base.

The French scheme involves a benefit «in kind» of a maximum of 4300 Francs per month, in the form of a cheque or voucher with which an outside carer or service provider can be remunerated directly. The amount of the cheque depends on the dependent individual's income. If net taxable incomes does not exceed 9300 Francs per month, the individual qualifies for the entire benefit, i.e. 4300 Francs. Thereafter, the benefit is digressive, ceasing altogether when net monthly income exceeds 13.000 Francs. Entitlement to the allowance also depends on the individual being granted dependent status by the sicknessinsurance fund. Assessment of this status is made by reference to the AGGIR table (3) - a national dependency-evaluation scale - which, based on the activities which the elderly person is unable to perform, indicates a score (measuring autonomy loss) which places the individual in one of 6 iso-resource categories.

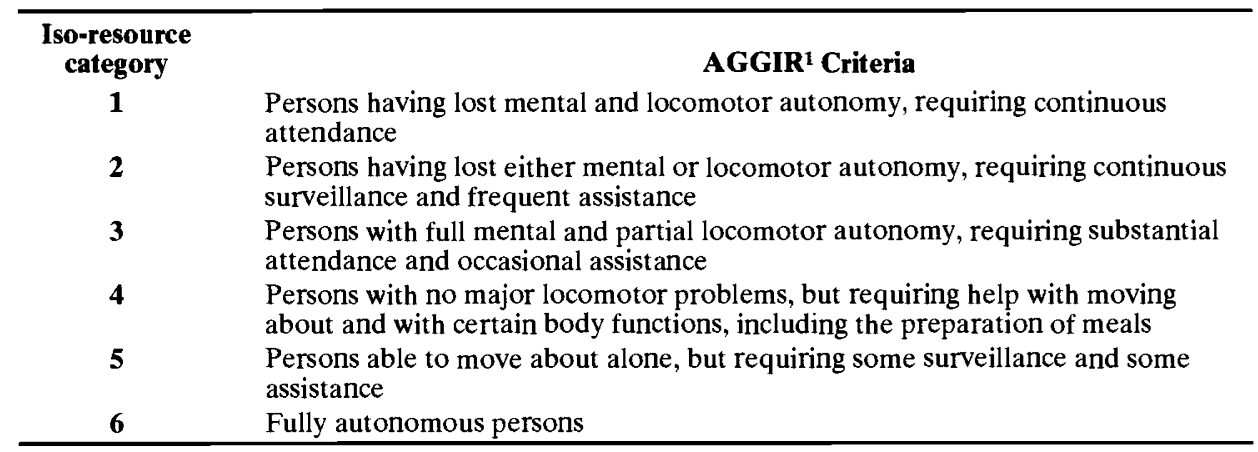

Dependent status is attributed to persons in categories $1,2 \& 3$ and confers entitlement to the autonomy allowance, subject to certain requirements regarding age and residence.

1 AGGIR: Iso-Resource Categorisation of Gerontological Autonomy, based on all tables and scales published by the National Gerontological Syndicate. 
For the time being, legislators in France have taken no final decision regarding entry into force of the autonomy allowance on 1 January 1997. It would, however, appear that for financial reasons the allowance will be phased-in. So that, initially, only the most vulnerable will be able to benefit from the dependency allowance, the resource ceiling having been deliberately set at a low level. As and when public finances allow, this ceiling will be progressively raised. The launch of the allowance is to be accompanied by a review of the rates practised by institutions where dependent persons reside. It would also appear that the income ceiling at which entitlement to the allowance ceases has been reduced from 9300 to 7700 Francs per month. Similarly, the criteria for entitlement are to be reviewed and made stiffer, particularly with regard to assessment of the dependent individual's existing situation and of the full range of benefits (in cash and kind) already enjoyed.

The slowness with which this dependency allowance scheme has been set up is due to the prevailing difficult economic circumstances. The Government's pressing need to get public finances in order does not allow for any new social measures without full assessment of cost implications and of the risk of escalation. Hence its caution and step-by-step approach.

The German and French schemes have two features in common. On the one hand, dependency-risk cover is achieved through social insurance guaranteeing a minimum amount which, while insufficient to meet real needs, does leave room for complementary cover. And, on the other, the decision to extend social insurance into a new area was taken unilaterally without advance consultation with the private entities likely to be operating therein. The shortcomings of the new schemes are thus immediately apparent: in Germany, if demographic trends live up to current predictions (a sharp increase in the number of dependent individuals after the year 2000 for the scheme risks reaching saturation point around 2020, because of lack of funds to finance benefits. In France, the problems are slightly different. They have to do with the time taken to get the scheme up and running and with the major reduction in the level of benefits, possibly in light of the German experience, compared to what was originally proposed. Right from the outset, lack of co-ordination with the major public and private partners has made it impossible to lay down sound foundations for the financing of dependency. It is, by contrast, this strategy of prior consultation that has been built into the British approach!

\subsection{The English model and the creation of a public-private partnership}

Launched in November 1995, the Government scheme in Britain is designed to make available to the dependent elderly an assistance package which provides more efficient protection of personal assets. At present, social assistance is a function of the dependent individual's asset level. Full benefits are available if the latter does not exceed $\$ 10.000$. Over and above that level, the dependent individual must shoulder part of the cost of care and its total cost if assets are over $£ 16.000$. This system tends, thereby, to weaken the dependent individual financially, obliging around 40.000 persons per year to sell or mortgage their property, as a rule their home, in order to pay for the cost of care. It was, however, difficult for the Government to create a new, entirely public, benefit, hence the idea of working in partnership with private insurers using existing schemes in the USA - in California, Connecticut and Indiana - as models. 
The scheme, details of which were published in a government report of May 1996, proposed two kinds of partnership, it being in the definition of means-test criteria that the partnership arrangement comes into play.

With the first kind of partnership, in implementing the resource ceiling conferring entitlement to State benefits, the local community will deduct $£ 1.50$ for every $£ 1$ of dependency insurance purchased with a private insurer. Thus, an amount, one and half times the total indemnity from the insurer, is added to the $£ 10.000$ basic asset level which pushes up the overall resource ceiling much higher than previously. In other words, if the insurance indemnity is $£ 40.000$, the resource ceiling beneath which the dependent individual is entitled to social dependency insurance is $£ 70.000$ instead of $£ 10.000$.

With the second partnership arrangement, when a person has for four years financed care from private insurance, the local community applies a mean test whereby $£ 1$ of social insurance is discounted for every $£ 1$ of private insurance. This discounting of $£ 15.000 \mathrm{com}$ bines with the existing $£ 10.000$ ceiling. Thus, for example, in the case of private insurance cover of $£ 80.000$, the aggregate resource ceiling climbs to $£ 105.000$.

With this system there are two advantages. On the one hand, the community (i.e. the taxpayer), thanks to individual accountability, is not alone in bearing the cost, and, on the other, the system saves the dependent individual from having to part with his or her property.

In order to establish a dialogue with insurance companies likely to be operating the new scheme and to get feedback, the Government launched a vast ideas-gathering campaign. In reply, the ABI (Association of British Insurers) has just published a report in which it suggests a number of modifications to the original plan. Stressing how unusual it is for a government to decide to consult in this way, the ABI makes the point that a partnership of this kind should have an extremely positive impact on the private dependency-insurance market, a branch that has never really taken off in the United Kingdom. Insurers should be able to benefit from the opportunity to diversify business by offering products which are more attractive to the insured since the level of cover required would be lower. It now remains for the Government to come up with a definition dependency. The ABI wants the latter to be in line with private-sector definitions, that is to say, ADL-based. Moreover, the Association would want it to be possible for dependency-insurance cover to be incorporated at the pension design stage. Since the details of the Bill are still far from being finalised, the consultation and opinion-gathering exercise between Government and private insurers should make for a scheme which is both viable and efficient. And yet, even if the partnership idea can serve as a model, the actual formulation of the allowance is by no means a simple task, and problems are likely to crop up at the implementation stage.

The time has clearly come for Governments to take a high-profile initiative in formulating a policy package for the dependent elderly, but one is, even so, bound to admit that attempts at provision so far have all been via private insurance.

\section{Private insurers were the first to offer tailored-made dependency insurance: the scope of their initiative}

Private insurers were the first to enter the free field of dependency insurance - as of the late 70's in the USA, in France as of the mid 80's, and in the UK as of the beginning of 
the 90's. But fear of abuse of the system as well as the difficulty insurers faced in defining dependency meant asking high prices for dependency products which failed to live up to commercial expectations. The reawakening of individual interest in recent years, however, has highlighted the need for protection against this kind of risk, while product diversity as well as lack of homogeneity (definitions and benefits) in the policies offered by insurers have made it very difficult for the general public to adopt a coherent and rational approach to the dependency-risk issue.

Indeed, private insurance frequently has to contend with the problems of moral hazard (insurance-induced overconsumption) and anti-selection (the lure of the higher risk). In dependency insurance, avoiding these problems is especially difficult unless contracts can be made sufficiently specific so as to tease out insured preference thus making it possible to set premiums at appropriate levels. Although theoretically attractive, this approach proves difficult in practice due to a shortage of statistical data upon which to base an objective definition of dependency. There is, as a result, an enormous temptation to raise premia disproportionately in order to provide an adequate safety margin without, at the same time, being able to provide any guarantee of a positive outcome.

Moreover, by setting premia too high, the insurer frightens away many would-be insured, leaving only the well-off in a position to afford the guarantee. The net result is to exclude an entire section of the population from dependency cover. The «all private» approach cannot therefore be seen as a solution to the problem of dependency-cover provision. Dependency risk, moreover, cannot be analysed in the short term. For premia for a given year cannot be calculated on the basis of expected indemnity costs for the year in question which means that the strict mutualist principle of risk sharing no longer obtains. Policies must therefore be balanced out and made to function on a capitalistic basis whereby premia accumulated over the capital-constitution phase serve to fund expenditure when the insured becomes dependent. Dependency insurance is, then, but one aspect of the broader issue of management of old-age, and can, and should, be planned for throughout the life cycle, with insurance acting as a resource-release mechanism over time.

And finally, there is the problem of fixing the level of the insurance premium. Costing dependency basically involves calculating the wage costs incurred by providing a given type of care, with an upward adjustment for medication-intensive cases. Although as a rule non-technical in nature and not particularly time-consuming, such care is, even so, frequently unrewarding and involves provision of a customised package without which payment of a capital sum or annuity will be of no avail to the patient. The only other alternative is for such care to be provided directly by the family which is tantamount to our relying, for a solution to the problem of dependency in the elderly, on intergenerational solidarity within the family whose efficacy we know to be diminishing.

But the targets the private insurer sets himself are by no means the same as those which social insurance sets itself. The notions of profitability and of a maximum return are essential facets of the private insurer's corporate strategy, and his agreement to cover dependency risk will only be forthcoming if he counts on minimum profitability to ensure survival in business.

World-wide, the main market is in the USA. At the time of its launch in the 70's, dependency insurance did not achieve the immediate success expected of it. Early pro- 
ducts were not suited to the real needs of the individual; they were costly, provided no cover for Alzheimer's disease, and above all offered no annuity guarantee. The market really began to take off in the mid 80's once insurers had had time to redesign their product. The recently published study by the Health Insurance Association of America entitled: «Long Term Care Insurance in 1994» indicates that close on 4 million dependencyinsurance policies have been sold since the mid 80's, mainly (almost 80\%) through associations. Annual average growth is $25 \%$ and, although a slight slackening was observed in 1993 and 1994 (awaiting a reform of the social health service), failure of the Clinton initiative has brought home to the population the need for personal management of dependency risk. For several years now, insurers have been attempting to promote this branch in various ways outside the associative route. Two new formulae have thus appeared on the market: incorporation of dependency insurance in enterprise welfare schemes, and as a complement to Life Assurance. These new formulae accounted for $17 \%$ of sales in 1987; today this figure has risen to $40 \%$. Dependency insurance is, even so, a product purchased in the main by better-off elderly households. Age for age, the average income and assets of these purchasers are well above national average. Acquisition of private dependency cover appears to be a function of various social (education, for example) and economic (income and assets) factors which make access to this cover more difficult for some than for others. There are those, therefore, who are bound to be excluded.

\section{Conclusion}

To sum up, then, we have, on the one hand, the «all public» approach which seems not to be feasible due to the current difficulties facing social welfare systems, and, on the other, the «all private» approach which appears ideal neither for the insured's nor the insurer's point of view. It would seem sensible, therefore, to be thinking in terms of a mixed approach to funding dependency, where public and private insurance are complementary, broadly capable of meeting the real needs of the dependent elderly in respect of care, assistance and accommodation. The English model offers a solution which seems to be on the right lines. Although provision of basic cover by the State is a matter of political will, beyond the reach of private insurers, a putting of heads together by all those concerned could and should produce an economically workable solution.

An agreed public-private solution and mixed financing of dependency seems to us to be best adapted to the prevailing circumstances of social welfare systems. Everywhere in Europe, «all public» strategies have revealed their limitations, and in an economic context of weak growth and public deficit the setting up of yet another social insurance is barely conceivable. Nonetheless, a common and public definition of dependency, recognised and accepted by all those concerned, is essential, since a multiplicity of definitions tends to deprive dependency insurance of legitimacy in the eyes of would-be insured while the risk to be covered remains a substantial one. Once the social welfare system explicitly recognises dependency in the elderly as an official state, the definition of that state as well as the criteria to be used for assessment of autonomy can then be used as bench-marks by insurers who, in turn, will be able fully to play their part as purveyors of second-level cover. Dependency insurance is still perceived by the insureds themselves as an annuity insurance. But the well-publicised concern of the authorities has helped to raise people's awareness of the risk and, above all, of the high cost it represents for dependent individuals and their families. 
The idea of an overall old-age welfare package which includes financial provision and provident arrangements seems to be taking shape. Such a provident scheme which covered the health costs of the elderly, whether able-bodied or dependent, would constitute a firstlevel facility for which the State would be responsible and which could be financed from taxes. Since it covered the entire population, a first-level facility of this kind would provide effective protection against anti-selection risk. A second level, in complement to the first, should be a compulsory component of collective welfare contracts set up by enterprise and pension funds. And finally, a third-level insurance could be available as an option to individuals. The proposed three-tier system would thus marry together solidarity, mutualisation and personal providence, and stand as a guarantee of the survival of our social systems.

\section{REFERENCES}

Association of British Insurers, «Comments of the Association of British Insurers on the Government's consultation paper: a new partnership for care in old age», London, June 1996.

BOUGET, D., TARTARIN, R., FROSSARD, M., et TRIPIER, P., «Le prix de la dépendance des personnes âgées selon leur mode d'hébergement», La Documentation Française, Paris, 1990.

CORONEL, S. and CAPLAN, C., «Long term Care insurance in 1994», Health Insurance Association of America, Washington, Mars 1996.

GARDENT H. - SPINGA J. - BOUNOT A., «Dépendance des personnes âgées : Expérimentation simultanée de six grilles de dépendance», Centre Technique Nationale d'Etudes et de Recherches sur les Handicaps et les Inadaptations, Paris, Septembre 1988.

Health Insurance Association of America, «Who buys Long Term Care insurance?» 1994-95 profiles and innovations in a dynamic market», Washington, 1996.

Institut National des Invalides, «Classification internationale des handicaps : du concept à l'application», Actes du colloque CTNERHI, Paris, 28-29 novembre 1988.

KATZ, S., «Progress in development of the index of Activities of Daily Living», The Gerontologist, 1970.

KATZ, S., «Studies of illness in the Aged: the index of Activities of Daily Living», Journal of the American Association, 1963.

«Données sociales et économiques sur la vieillesse», Gérontologie et Société, numéro spécial, no 71 , Paris, décembre 1994. 